\title{
Prevalence, awareness, treatment, and control of hypertension in older people: results from the population-based KORA-age 1 study
}

Samuel Muli ${ }^{1,2^{*}}$, Christa Meisinger ${ }^{2,3}$, Margit Heier ${ }^{4,5}$, Barbara Thorand ${ }^{4}$, Annette Peters ${ }^{4}$ and Ute Amann ${ }^{2,3}$

\begin{abstract}
Background: Hypertension remains a significant modifiable risk factor for cardiovascular diseases and a major determinant of morbidity and mortality. We aimed to describe sex-stratified age-standardized estimates of prevalence, awareness, treatment and control of hypertension, and their associated factors in older adults.

Methods: The KORA-Age1 is a population-based cross-sectional survey carried out in 2008/2009 on individuals aged 65-94 years in Augsburg region, Germany. Blood pressure measurements were available for 1052 out of 1079 persons who participated in the physical examination. Factors associated with prevalence, awareness and control of hypertension were investigated by multivariable logistic regression.

Results: The overall prevalence of hypertension $(\geq 140 / 90 \mathrm{mmHg}$ ) was $73.8 \%$ [95\% confidence interval (Cl), 69.377.9], representing $74.8 \%(95 \% \mathrm{Cl}, 68.4-80.2)$ in men and $73.5 \%(95 \% \mathrm{Cl}, 66.8-79.3)$ in women. Among those with hypertension, $80.2 \%(95 \% \mathrm{Cl}, 75.3-84.4)$ were aware of their hypertensive condition and $74.4 \%(95 \% \mathrm{Cl}, 69.2-79.1)$ were on treatment for hypertension. Among those aware of their hypertension status, $92.8 \%(95 \% \mathrm{Cl}, 88.8-95.6)$ were on treatment and $53.7 \%(95 \% \mathrm{Cl}, 47.0-60.1)$ had their blood pressure controlled. Hypertension was more frequent in individuals who were older, obese, or had diabetes. Higher education attainment or presence of comorbidities was associated with higher level of hypertension awareness. Individuals taking three antihypertensive drug classes were more likely to have controlled hypertension compared with those taking one antihypertensive drug class, odds ratio (OR), 1.85 (95\% Cl, 1.14-2.99).

Conclusion: Our findings identified high prevalence of hypertension and relevant health gaps on awareness, treatment and suboptimal control of hypertension in older adults in Germany. Screening for hypertension should especially target older adults with low educational attainment and 'healthy' elderly with less contact to physicians.
\end{abstract}

Keywords: Prevalence, Awareness, Treatment, Control, Hypertension, Older adults

\footnotetext{
* Correspondence: mulisamtisya@gmail.com

${ }^{1}$ Institute for Medical Informatics, Biometry, and Epidemiology,

Ludwig-Maximilians-Universität München, Munich, Germany

${ }^{2}$ Helmholtz Zentrum München, German Research Center for Environmental

Health $(\mathrm{GmbH})$, Independent Research Group Clinical Epidemiology,

Ingolstädter Landstraße 1, 85764 Neuherberg, Germany

Full list of author information is available at the end of the article
}

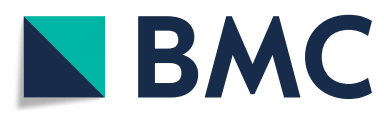

(c) The Author(s). 2020 Open Access This article is licensed under a Creative Commons Attribution 4.0 International License, which permits use, sharing, adaptation, distribution and reproduction in any medium or format, as long as you give appropriate credit to the original author(s) and the source, provide a link to the Creative Commons licence, and indicate if changes were made. The images or other third party material in this article are included in the article's Creative Commons licence, unless indicated otherwise in a credit line to the material. If material is not included in the article's Creative Commons licence and your intended use is not permitted by statutory regulation or exceeds the permitted use, you will need to obtain permission directly from the copyright holder. To view a copy of this licence, visit http://creativecommons.org/licenses/by/4.0/. The Creative Commons Public Domain Dedication waiver (http://creativecommons.org/publicdomain/zero/1.0/) applies to the data made available in this article, unless otherwise stated in a credit line to the data. 


\section{Background}

Cardiovascular diseases (CVDs) are a leading cause of premature death and morbidity, and a major global public health concern [1]. In 2016, it was estimated that 17.9 million people died from CVDs, which represented $31 \%$ of all-cause mortality in that year [2]. Hypertension is widely recognized as the most significant modifiable risk factor for CVDs [3], and a leading contributor of disabilityadjusted life years [4]. Moreover, hypertension remains a significant concern for public health systems due to the high prevalence of its associated risk factors. Physical inactivity, alcohol consumption, smoking, and poor dietary habits are highly prevalent in the general population, yet have a lifelong bearing on the risk of hypertension [5].

The incidence of hypertension significantly rises with increasing age [6, 7]; hence, it is more prevalent among older adults than in young and middle-aged population [4]. $\mathrm{Nu}-$ merous population-based surveys in various regions of the world estimate that 7 out of 10 adults, 65 years and older, have been diagnosed with elevated blood pressure [8-10]. This trend is likely to persist, as the population of older persons in high-income countries continues to grow [11]. In some countries such as the U.S., even though the trends in incidence of hypertension have only slightly changed [12], the absolute number of people with hypertension is ever growing due to the aging population [13]. Some studies observed that about $24-30 \%$ of older adults with hypertension were not aware of their hypertension status [9, 14, 15], and about $32 \%$ were not on treatment $[9,15]$. In the same studies, the proportion of treated and controlled hypertension was barely $50 \%[9,14,15]$, which suggests that treatment and controlled hypertension in older adults is suboptimal - and an issue of great public health interest. In Germany, epidemiological studies on prevalence, awareness, treatment and control of hypertension have only been conducted in adults aged 18-79 years [16], but so far not in the very old population. Therefore, the aim of this study is to determine the prevalence, awareness, treatment and control of hypertension, and their associated factors in older people aged 65-94 years from the general population in Germany.

\section{Methods}

\section{Study design and population}

The KORA-Age1 study was carried out in 2008/2009 within the framework of the multidisciplinary Cooperative Health Research in the Augsburg Region (KORA) on individuals aged 65-94 [17]. Briefly, 5991 persons of the previous four KORA surveys conducted between 1985 and 2001, who were born in 1943 or earlier, still alive and living in the study region, were mailed a brief self-administered questionnaire between November 2008 and September 2009. Furthermore, an extended telephone interview was conducted on 4127 study participants to collect more specific data on morbidity and health status (e.g., kidney and heart diseases). A sex- and age-stratified subsample (100 persons per stratum) of 2005 persons were invited for physical examination (e.g., blood pressure measurements); 1079 (53.8\%) participated, and of these, 963 persons were examined at the KORA study center, 94 were examined during a home visit, and 22 got only a short interview [15]. Detailed information on study design and sampling is provided elsewhere $[18,19]$.

\section{Study variables \\ Measurement of blood pressure and anti-hypertensive medications}

Three blood pressure measurements were performed on the right arm (after a rest of at least $5 \mathrm{~min}$ ), within an interval of $3 \mathrm{~min}$, in a seated position using an automatic digital oscillometer (HEM 705CP-II Omron Corporation Japan). Cuffs were adjusted appropriately for arm girth of the participant. The mean of the second and third measurements was determined and adopted as the blood pressure reading for the present study. All blood pressure measurements were performed on a single occasion.

All participants were requested to provide medications used within the last 7 days preceding the examination appointment. Medications in KORA studies were assigned as 'antihypertensive medications' only if the compounds taken were classified by the most recent guidelines of the German Hypertension Society [20]. In addition, categorization by antihypertensive drug classes based on the German anatomic therapeutic chemical (ATC) classification was used for the following: diuretics (C03, C02L, C07B-C07D, C08G, C09BA or C09DA), beta blockers (C07), angiotensin converting enzyme (ACE) inhibitors (C09A or C09B), angiotensin receptor blockers (ARBs) (C09C or C09D), renin-inhibitors (C09XA), calcium channel blockers (CCBs) (C08, C07FB22, $\mathrm{C} 09 \mathrm{BB}$ or $\mathrm{C} 09 \mathrm{DB})$ and other antihypertensives $(\mathrm{CO} 2$ without C02KX, C02KP (phytotherapy) and C02KH (homeopathy or anthroposophy)).

\section{Definitions}

The study adopted widely recognized standard definitions for the study outcomes, namely hypertension, awareness, treatment, and control of hypertension.

\section{Hypertension}

Participants were identified as hypertensive if they had systolic blood pressure (SBP) $\geq 140 \mathrm{mmHg}$ or diastolic blood pressure (DBP) $\geq 90 \mathrm{mmHg}$ or their blood pressure was controlled as a result of taking antihypertensive medications. Since these medications may also be indicated for health conditions other than hypertension, information on antihypertensive medication use was only utilized for identifying hypertensive cases if the person confirmed to be aware of hypertension. Similar approach is applied in other studies in Germany [5, 21]. 


\section{Awareness}

Individuals with hypertension who responded with "yes" to the following question: "have you ever been diagnosed by a doctor or health professional with elevated blood pressure?" were considered as being aware of their hypertension.

\section{Treatment}

Hypertensives aware of their hypertension diagnosis, who were on at least one of the antihypertensive medications as identified above.

\section{Control}

Treated hypertensives who at the time of measurements had their blood pressure below the target goals i.e. $\mathrm{SBP}<140 \mathrm{mmHg}$ and $\mathrm{DBP}<90 \mathrm{mmHg}$.

\section{Special patient groups}

Stronger blood pressure target goals for high-risk patient groups such as diabetes are recommended in some guidelines [22]. In a subgroup analysis considering this group, controlled hypertension was defined as blood pressure below or equal to $130 / 80 \mathrm{mmHg}$ [22].

\section{Covariates}

Besides age and sex, the following covariates were considered and described in detail. Educational attainment levels were classified according to highest academic qualification, namely low level ('Hauptschule'), middle level ('Realschule'), high level ('Abitur' or higher level). Smoking status was categorized into current smoker (for individuals who smoke regularly or irregularly), former smokers, and never smokers. Height and weight of participants were measured during physical examination, and the body mass index (BMI) calculated by dividing weight by height squared $(\mathrm{kg} /$ $\mathrm{m}^{2}$ ), and classified according to the World Health Organization (WHO) guidelines: underweight: < 18.5, normal $\geq 18.5$ and $<25$, overweight $\geq 25$ and $<30$, and obese $\geq 30$. Additionally, physical activity was assessed using standardized interviews in which participants reported their weekly leisure-time physical activity during summer and winter. Those who reported almost no sports activity or about $1 \mathrm{~h}$ per week irregularly, were grouped as inactive. Participants who reported leisure-time physical activity of $1 \mathrm{~h}$ or more per week regularly in winter and summer, were grouped as active. Comorbidity status of participants was self-reported for specific conditions such as heart and kidney diseases, diabetes mellitus, previous stroke, and cancer diagnosis in the last 3 years. For diabetes mellitus, use of antidiabetic medications (A10) additionally contributed to the final allocation as diabetic person. If participant was unable to answer interview questions, a proxy interview was conducted.

\section{Statistical analyses}

Descriptive statistical analyses were performed to characterize the distribution of blood pressure, antihypertensive medication and drug classes, and to determine the prevalence, awareness, treatment and control of hypertension. Estimates of these study outcomes (per 100 persons) were age-standardized using the German population as on 31.12.2009. 10-year age groups were created and population weights for each group determined. Since a specific population weight for individuals aged above 90 years was not available, the nearest population weight ( 85 years and above) was used. To explore group differences between individuals with hypertension and those without, student ttests and Mann-Whitney $U$ tests were applied appropriately on continuous variables, and chi-squared test on categorical variables. Association of covariates and the prevalence, awareness, treatment and control of hypertension were explored using logistic regression analyses. In developing the logistic regression models, four dependent variables were identified: hypertension status among all participants (yes $=1$, no $=0$ ), awareness among hypertensive individuals (aware $=1$, unaware $=0$ ), treatment among aware hypertensives (treated $=1$, untreated $=0$ ), and control of blood pressure among treated hypertensives (controlled $=1$, uncontrolled $=0$ ). This analysis approach is reported in other studies [7, 14, 15, 23]. Since there was no significant interaction between sex and the four dependent variables $(p<0.05)$, the logistic regression models were not stratified by sex. Purposeful selection of covariates for building multivariable logistic regression models was conducted, beginning with univariate analysis, each covariate at a time [24]. Covariates were included in multivariable models if univariate analysis showed level of significance of p-value $<0.25$ [24] or if they are documented in literature as potential confounders. Analyses of variance and likelihood ratio tests were also performed on the adjusted multivariable models. The "treatment among aware" model (treated $=601$, untreated $=37$ ) was dropped due to the small sample size of the untreated group in terms of events per variable (EPV), which showed poor predictive performance. The acceptability of the multivariable models was evaluated using the Pearson-Chi-Square goodness of fit test. P-values $<0.05$ were considered statistically significant. The $\mathrm{R}$ program 3.2.3 was used to conduct the analyses.

\section{Results}

Out of the 1079 physically examined study participants, blood pressure measurements were available for 1052 persons, representing 50.3\% men and 49.7\% women. Out of these, 790 participants were identified as hypertensive (397 males and 393 females), representing unweighted prevalence of $75.1 \%$. Table 1 summarizes the demographic and clinical characteristics of the population stratified by hypertension status. 
Table 1 Characteristics of the study participants stratified by hypertension status

\begin{tabular}{|c|c|c|c|c|}
\hline Variable & Total $(n=1052)$ & Hypertension $(n=790)$ & No Hypertension $(n=262)$ & $P$-value ${ }^{\dagger}$ \\
\hline Sex & & & & 1.000 \\
\hline Male & $529(50.3)$ & $397(50.3)$ & $132(50.4)$ & \\
\hline Female & $523(49.7)$ & $393(49.7)$ & $130(49.6)$ & \\
\hline Age (mean $( \pm S D))$ & $75.9(6.6)$ & $76.2(6.4)$ & $75.1(6.9)$ & 0.020 \\
\hline Age (years) (\%) & & & & 0.020 \\
\hline $65-69$ & $227(21.6)$ & $157(19.9)$ & $70(26.7)$ & \\
\hline $70-74$ & $227(21.6)$ & $163(20.6)$ & $64(24.4)$ & \\
\hline $75-79$ & $241(22.9)$ & $192(24.3)$ & $49(18.7)$ & \\
\hline $80-84$ & $232(22.1)$ & $186(23.5)$ & $46(17.6)$ & \\
\hline $85-94$ & $125(11.9)$ & $92(11.6)$ & $33(12.6)$ & \\
\hline Living with partner (\%) & $656(63.0)$ & $420(79.7)$ & $236(45.9)$ & $<0.001$ \\
\hline Smoking status (\%) & & & & $<0.001$ \\
\hline Never & $565(53.7)$ & $417(52.8)$ & $148(56.5)$ & 0.504 \\
\hline Ex-smoker & $438(41.6)$ & $337(42.7)$ & $101(38.5)$ & \\
\hline Current smoker & $49(4.7)$ & $36(4.6)$ & $13(5.0)$ & \\
\hline Education ${ }^{\mathrm{a}}(\%)$ & & & & 0.112 \\
\hline Low level & $717(68.2)$ & $552(69.9)$ & $165(63.0)$ & \\
\hline Middle level & $190(18.1)$ & $136(17.2)$ & $54(20.6)$ & \\
\hline High level & $145(13.8)$ & $102(12.9)$ & $43(16.4)$ & \\
\hline BMI $\left(\mathrm{kg} / \mathrm{m}^{2}\right)(\%)$ & & & & $<0.001$ \\
\hline Underweight $(<18.5)$ & $1(0.1)$ & $0(0.0)$ & $1(0.4)$ & \\
\hline Normal (18.5-24.9) & $213(20.2)$ & $142(18.0)$ & $71(27.1)$ & \\
\hline Overweight (25-29.9) & $515(49.0)$ & $379(48.0)$ & $136(51.9)$ & \\
\hline Obese $(\geq 30)$ & $323(30.7)$ & $269(34.1)$ & $54(20.6)$ & \\
\hline BMI (median (IQR)) & $27.9(25.4-30.8)$ & $28.3(25.8-31.2)$ & $26.9(24.8-29.5)$ & $<0.001$ \\
\hline Physically active (\%) ${ }^{\text {b }}$ & $561(53.3)$ & $422(53.4)$ & $139(53.1)$ & 0.975 \\
\hline Heart diseases $(\%)$ * & $327(31.1)$ & $250(31.6)$ & 77 (29.4) & 0.544 \\
\hline Kidney diseases (\%) * & $50(4.8)$ & $42(5.3)$ & $8(3.1)$ & 0.185 \\
\hline Diabetes (\%) ${ }^{\mathrm{c}}$ & $187(17.8)$ & $167(21.2)$ & $20(7.6)$ & $<0.001$ \\
\hline Stroke $(\%) *$ & $88(8.4)$ & $68(8.6)$ & $20(7.6)$ & 0.715 \\
\hline
\end{tabular}

$\dagger p$ value obtained from comparing differences between hypertensives and non-hypertensives using $\mathrm{X}^{2}$-test for categorical variables, $\mathrm{t}$-test for age difference, and Mann-Whitney $\mathrm{U}$ test for BMI medians

a Based on the highest academic qualification: Low level ('Hauptschule'), Middle level ('Realschule'), High level ('Abitur' or higher level)

b Physical activity: self-reported sporting activity during leisure time of $1 \mathrm{~h}$ or more per week, regularly or irregularly

${ }^{\mathrm{c}}$ Diabetes mellitus was both self-reported and confirmed also through use of antidiabetic medications

* Self-reported comorbidities

$S D$ Standard deviation of the observed age in our sample; BMI Body mass index; IQR Interquartile range

The participants' age ranged between 65 and 94 years, with mean age of 75.9 years $(\mathrm{SD}=6.6)$. There was a significant age difference between hypertensives and non-hypertensives, representing means of $76.2(\mathrm{SD}=$ $6.4)$ and $75.1(6.9)$ years respectively $(p=0.020)$. Additionally, there were significant differences in the BMI for participants with hypertension who had a median BMI of 28.3 (IQR $=25.8-31.2)$ compared to 26.9 $(\mathrm{IQR}=24.8-29.5)$ in those without hypertension $(\mathrm{p}<$ 0.001 ). There was a significantly higher frequency of obesity and diabetes in individuals with hypertension compared to those without hypertension, representing a $34.1 \%$ vs. $20.6 \%, p<0.001$ and $21.2 \%$ vs. $7.6 \%, p<0.001$, respectively.

\section{Prevalence, awareness, treatment and control of hypertension}

Figure 1 provides a schematic representation of the frequency, awareness, treatment, and control of hypertension in the KORA Age-1 study.

As summarized in Table 2, the overall age-standardized prevalence of hypertension was $73.8 \%$ (95\% CI: 69.3-77.9), 


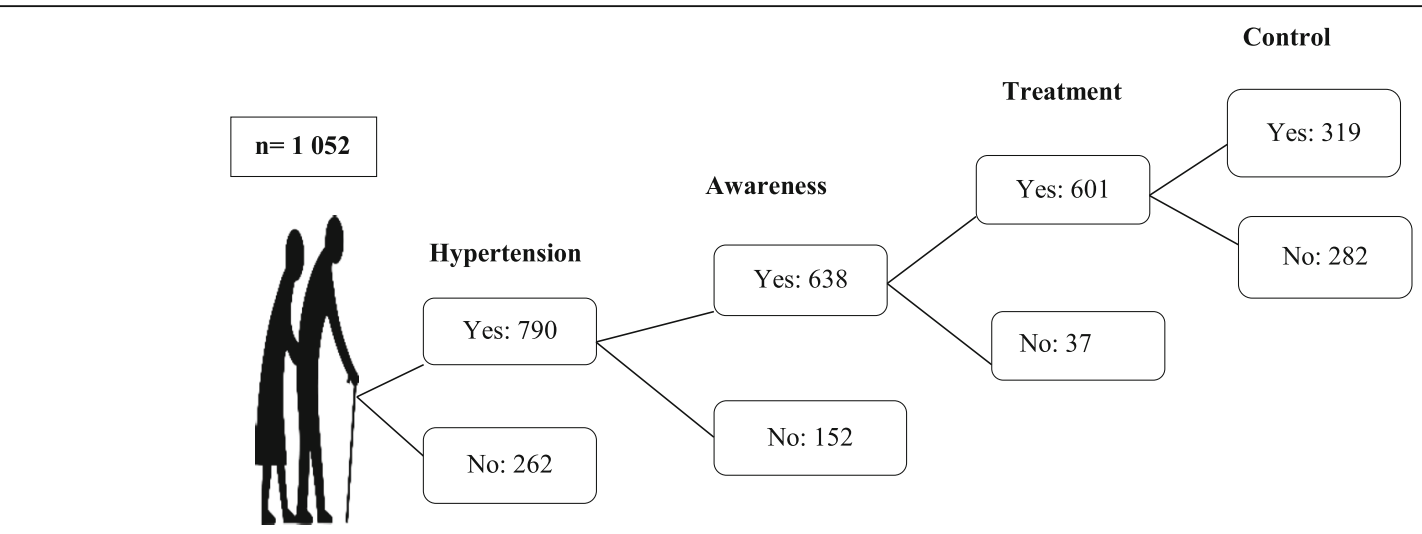

Fig. 1 Flow diagram showing the frequency, awareness, treatment and control of hypertension in KORA-Age 1 study

with men having slightly higher prevalence of hypertension than women $(74.8 \%$ vs. $73.5 \%)$. The frequency of hypertension was lowest in the group 65-74 years with $70.5 \%$ (95\% CI: 66.0-74.6) and highest in participants aged $75-84$ years with $79.9 \%$ (95\% CI: 76.0-83.4). Among individuals with hypertension $(\mathrm{n}=790), 80.2 \% \quad(95 \%$ CI: $75.3-84.4)$ affirmed having been diagnosed with hypertension; hence, were considered as being aware of their hypertension status. The level of awareness increased gradually with age, and was higher in women than in men $(81.3 \%$ vs. $78.3 \%)$.

Overall, in individuals with hypertension, $74.4 \%$ (95\% CI: 69.2-79.1) were on antihypertensive treatment, and the frequency of treated hypertension increased with age. However, considering treatment only among those aware of their status, 92.8\% (95\% CI, 88.8-95.6) were on antihypertensive medication, and 53.7\% (95\% CI: 47.0-60.1) of the treated hypertensives had attained blood pressure below 140/90 $\mathrm{mmHg}$. The frequency of optimal blood pressure control slightly declined with age, and was lowest in the oldest group, 49.3\% (95\% CI: 37.7-61.0).

The distribution of SBP and DBP by 5 -year age groups is summarized in Fig. 2. The oldest group, 85-94 years, had the highest SBP mean of $146.8 \mathrm{mmHg}$, but had the lowest DBP mean of $73.3 \mathrm{mmHg}$.
Results of multivariable analysis of factors associated with prevalence, awareness and control of hypertension

The results of the multivariable logistic models are summarized in Table 3. Briefly, the prevalence of hypertension increased with increasing age for age group 75-79 years (OR 1.79, 95\% CI: 1.11-2.72), and for age group 80-84 years (OR 1.95, 95\% CI: 1.22-3.12), and declined beyond the age of 85 years, (OR 1.41, 95\% CI: 0.80 2.47), $p=0.2337$ in comparison to age group 65-69 years. There was higher frequency of hypertension in individuals with obesity compared with those with normal weight (OR 2.14, 95\% CI: 1.39-3.29). Individuals with diabetes were also more likely to have hypertension compared to non-diabetic persons (OR 2.82, 95\% CI: 1.70-4.70). There were no statistically significant differences in hypertension prevalence with respect to other sociodemographic characteristics such as sex, living with partner, education attainment, and lifestyle factors such as smoking status and physical activity.

The level of education had significant influence on awareness status. Individuals with the highest educational attainment were more likely to be aware of their blood pressure status compared to individuals with low education (OR 2.40, 95\% CI: 1.20-4.80). Having comorbidities was also associated with higher odds of being aware: obesity (OR 1.97, 95\% CI: 1.14-3.42), heart disease (OR 2.38, 95\% CI: 1.46-3.87), stroke (OR 4.45, 95\%

Table 2 Prevalence, awareness, treatment and control of hypertension by age and sex

\begin{tabular}{llllll}
\hline & Age (years) & Prevalence $(n=1052)$ & Awareness $(n=790)$ & $\begin{array}{l}\text { Treatment among aware } \\
\text { hypertensives }(n=638)\end{array}$ & $\begin{array}{l}\text { Control among treated } \\
(n=601)\end{array}$ \\
\hline Male & $65-94$ & $74.8(68.4-80.2)^{a}$ & $78.3(71.1-84.2)^{a}$ & $93.9(87.9-97.1)^{a}$ & $52.5(43.2-61.5)^{a}$ \\
Female & $65-94$ & $73.5(66.8-79.3)^{a}$ & $81.3(74.0-87.0)^{a}$ & $92.6(86.1-96.4)^{a}$ & $54.9(45.3-64.2)^{a}$ \\
Total & $65-74$ & $70.5(66.0-74.6)$ & $78.4(73.5-82.7)$ & $90.8(86.4-93.9)$ & $54.4(47.7-60.9)$ \\
& $75-84$ & $79.9(76.0-83.4)$ & $82.0(77.7-85.7)$ & $96.1(93.2-97.8)$ & $53.0(47.2-58.8)$ \\
& $85-94$ & $73.6(64.8-80.9)$ & $83.7(74.2-90.3)$ & $97.4(90.1-99.5)$ & $49.3(37.7-61.0)$ \\
& $65-94$ & $73.8(69.3-77.9)^{a}$ & $80.2(75.3-84.4)^{a}$ & $92.8(88.8-95.6)^{a}$ & $53.7(47.0-60.2)^{a}$ \\
\hline
\end{tabular}

${ }^{\mathrm{a}}$ Age-standardized according to the distribution of the Germany population, 31 December 2009 


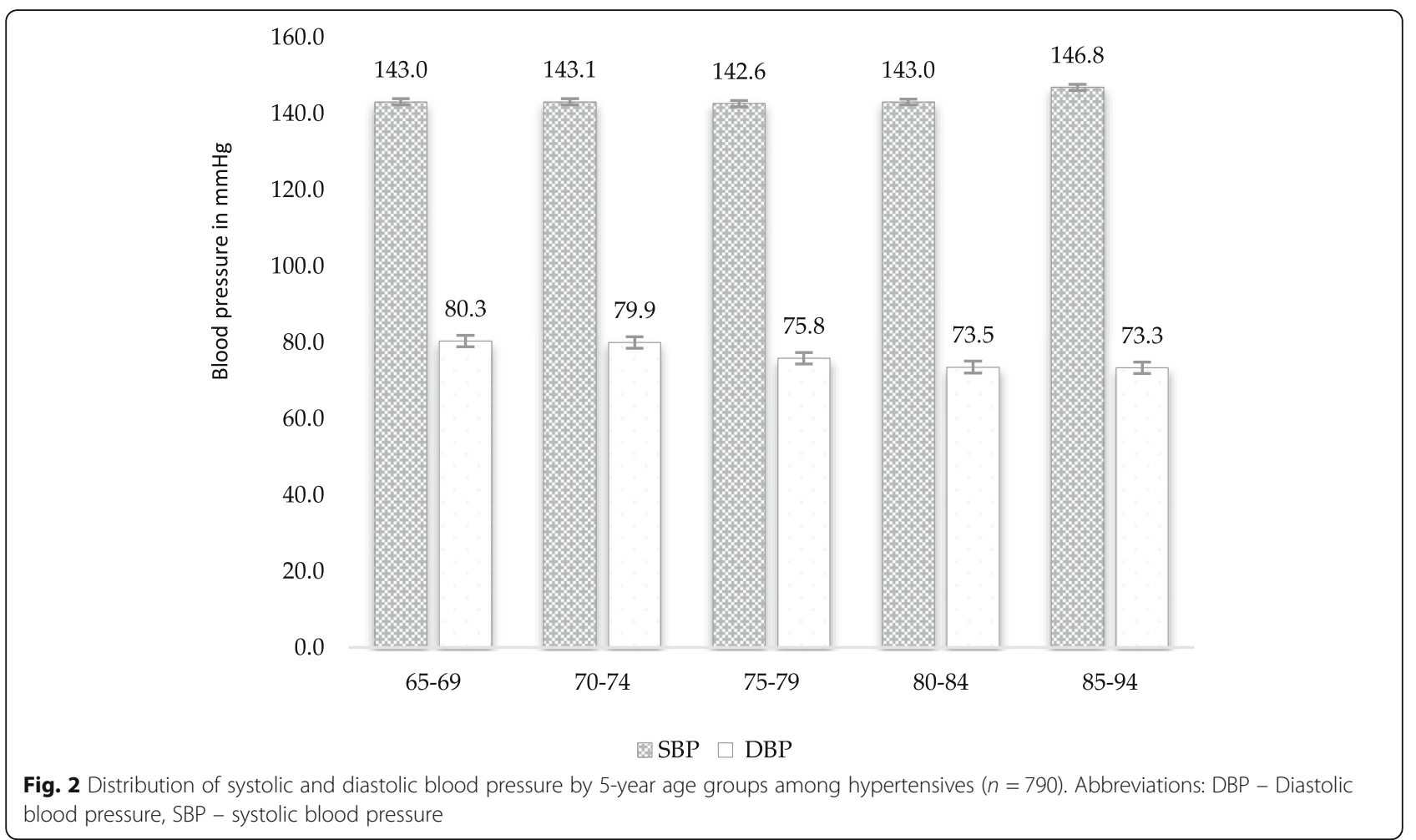

CI: 1.36-14.62), and diabetes (OR 2.05, 95\% CI: $1.17-$ 3.58), compared to individuals without the respective comorbid status.

There were no statistically significant differences with respect to sociodemographic characteristics or presence of comorbidities and control of blood pressure. However, treated hypertensives were more likely to have controlled blood pressure if under three antihypertensive drug classes (OR 1.85, 95\% CI: 1.14-2.98) compared to those on monotherapy. Taking more than three antihypertensive drug classes was not associated with statistically significant higher odds of being controlled (OR 1.24, 95\% CI: $0.68-2.27), p=0.490$ compared to monotherapy.

\section{Diabetes and blood pressure control}

Multivariable adjusted regression analysis considering controlled hypertension among diabetic individuals as blood pressure $\leq 130 / 80 \mathrm{mmHg}$, showed that treated hypertensives with diabetes were less likely to have controlled blood pressure (OR 0.38, 95\% CI: 0.25-0.58) compared to non-diabetic hypertensives. As shown in Table 3, there was no statistically significant change in the rest of covariates of the hypertension control model.

\section{Discussion}

This study showed that the prevalence of hypertension in adults aged $65-94$ years was $73.8 \%$, translating to 3 out of 4 older adults having high blood pressure. The age-standardized prevalence of hypertension was slightly higher in men than women, and increased with age. Even though our data showed highest SBP in individuals aged 85-94 years, a guarded approach in clinical interpretation of these findings should be considered. Unlike in the middle-aged persons, high SBP in the very elderly (> 85 years) is not consistently associated with increased risk for CVD events [24, 25].

Being aware of one's hypertension status may be a motivation for positive lifestyle modification: increasing physical activity, moderating alcohol consumption, smoking cessation, and dietary changes. Since $80.2 \%$ of hypertensive persons in this study were aware of their hypertension status, and $92.8 \%$ of those aware were on treatment, this suggests that the burden of untreated hypertension might be attributed to lack of awareness. Considering evidence that treating hypertension in older persons markedly reduces the risk of cardiovascular complications and mortality [25], intensifying screening of hypertension in the elderly should therefore, be encouraged.

The present study showed that the proportion of controlled hypertension in the older German population is quite low $-53.7 \%$. We however, hypothesized that measuring blood pressure on a single occasion potentially underestimated the proportion of controlled hypertension. A 24-h ambulatory blood pressure monitoring, though hardly ever used in population-based observational studies, may detect 
Table 3 Results of the multivariable logistic regression models on factors associated with prevalence, awareness and control of hypertension

\begin{tabular}{|c|c|c|c|c|}
\hline Characteristics/variables & $\begin{array}{l}\text { Prevalence }(n=1039) \\
\operatorname{OR}^{\mathrm{a}}(95 \%, \mathrm{Cl})\end{array}$ & $\begin{array}{l}\text { Awareness }(n=780) \\
\text { OR }^{\mathrm{a}}(95 \%, \mathrm{Cl})\end{array}$ & $\begin{array}{l}\text { Control }(n=595) \\
\text { OR }^{a}(95 \%, C l)\end{array}$ & $\begin{array}{l}\text { Control }^{c}(n=595) \\
\text { OR }^{a}(95 \%, C l)\end{array}$ \\
\hline Sex (ref: Men) & 1 & 1 & 1 & 1 \\
\hline Women & $1.11(0.79-1.56)$ & $1.21(0.78-1.90)$ & $1.00(0.66-1.49)$ & $1.03(0.36-1.96)$ \\
\hline Age Groups (years) (ref: $\geq 65-69$ ) & 1 & 1 & 1 & 1 \\
\hline $70-74$ & $1.09(0.72-1.67)$ & $1.12(0.64-1.96)$ & $1.20(0.70-2.06)$ & $0.97(0.56-1.68)$ \\
\hline $75-79$ & $1.79(1.11-2.72) *$ & $1.12(0.64-1.95)$ & $1.18(0.69-2.02)$ & $0.97(0.57-1.66)$ \\
\hline $80-84$ & $1.95(1.22-3.12) * *$ & $1.19(0.66-2.15)$ & $0.91(0.53-1.56)$ & $0.70(0.40-1.21)$ \\
\hline $85-94$ & $1.41(0.80-2.47)$ & $1.26(0.59-2.69)$ & $0.81(0.42-1.58)$ & $0.78(0.40-1.54)$ \\
\hline Living with Partner (ref: No) & 1 & 1 & 1 & 1 \\
\hline Yes & $1.01(0.72-1.41)$ & $0.94(0.61-1.46)$ & $0.93(0.63-1.37)$ & $0.83(0.56-1.54)$ \\
\hline Education (ref: Low) & 1 & 1 & 1 & 1 \\
\hline Middle level & $0.88(0.60-1.29)$ & $1.58(0.93-2.66)$ & $1.55(0.98-2.44)$ & $1.59(1.01-2.51) *$ \\
\hline High level & $0.78(0.51-1.18)$ & $2.40(1.20-4.80) *$ & $0.84(0.51-1.37)$ & $0.91(0.55-1.51)$ \\
\hline Smoking Status (ref: Never) & 1 & 1 & 1 & 1 \\
\hline Ex-smoker & $1.19(0.86-1.65)$ & $0.76(0.50-1.16)$ & $1.19(0.82-1.74)$ & $1.12(0.76-1.64)$ \\
\hline Current smoker & $1.21(0.59-2.49)$ & $0.58(0.24-1.38)$ & $2.31(0.90-5.92)$ & $2.36(0.93-5.99)$ \\
\hline BMI (ref: Normal) & 1 & 1 & 1 & 1 \\
\hline Underweight $(<18.5)^{b}$ & $0.00(0.00-\infty)$ & - & - & - \\
\hline Overweight (25-30) & $1.33(0.93-1.91)$ & $1.44(0.88-2.36)$ & $0.81(0.50-1.34)$ & $0.87(0.53-1.43)$ \\
\hline Obese $(\geq 30)$ & $2.14(1.39-3.29) * * *$ & $1.97(1.14-3.42) *$ & $1.02(0.61-1.73)$ & $1.09(0.64-1.85)$ \\
\hline Physical Activity (ref: No) & 1 & 1 & 1 & 1 \\
\hline Yes & $1.26(0.92-1.72)$ & $0.85(0.57-1.27)$ & $0.89(0.63-1.26)$ & $1.04(0.73-1.48)$ \\
\hline Heart Disease (ref: No) & 1 & 1 & 1 & 1 \\
\hline Yes & $0.94(0.68-1.31)$ & $2.38(1.46-3.87)^{* * *}$ & $1.19(0.83-1.72)$ & $1.35(0.93-1.97)$ \\
\hline Stroke (ref: No) & 1 & 1 & 1 & 1 \\
\hline Yes & $1.01(0.58-1.75)$ & $4.45(1.36-14.62) *$ & $0.99(0.57-1.73)$ & $0.95(0.54-1.67)$ \\
\hline Kidney disease (ref: No) & 1 & 1 & 1 & 1 \\
\hline Yes & $1.94(0.88-4.30)$ & $1.85(0.62-5.48)$ & $1.31(0.64-2.71)$ & $1.02(0.49-2.12)$ \\
\hline Diabetes (ref: No) & 1 & 1 & 1 & 1 \\
\hline Yes & $2.82(1.70-4.70) * * *$ & $2.05(1.17-3.58) *$ & $0.86(0.57-1.29)$ & $0.38(0.25-0.58)^{* * *}$ \\
\hline Drug combinations ${ }^{c}$ (ref: [1]) & - & - & 1 & 1 \\
\hline 2 classes & - & - & $1.35(0.85-2.12)$ & $1.32(0.83-2.09)$ \\
\hline 3 classes & - & - & $1.85(1.14-2.99) *$ & $1.90(1.17-3.10) * *$ \\
\hline$\geq 4$ classes & - & - & $1.24(0.68-2.27)$ & $1.22(0.66-2.27)$ \\
\hline
\end{tabular}

Abbreviations: $\mathrm{Cl}$ Confidence interval; OR Odds ratio; $B M I$ Body mass index expressed as $\mathrm{kg} / \mathrm{m}^{2}$;

${ }^{*} p$ value $<0.05 ;{ }^{* *} p$ values $<0.01 ;{ }^{* * *} p$ value $<0.001$

${ }^{a}$ The odds ratio from multivariable logistic regression, adjusted for other variables in the table

${ }^{b}$ only one individual was underweight and was observed to be non-hypertensive. The OR for this category is therefore, unreliable

c Subgroup analysis in which controlled hypertension was defined as blood pressure $\leq 130 / 80 \mathrm{mmHg}$ for individuals with diabetes mellitus

fluctuations in blood pressure and other symptoms in treated hypertensive subjects [13]. Our observations could also indicate a high prevalence of resistant hypertension in the population. In part, this may be due to non-adherence to treatment, which is common in older individuals [13]. Moreover, drug induced elevation of blood pressure was not evaluated in our study. It should be noted that some medications such as nonsteroidal anti-inflammatory drugs (NSAIDs) significantly elevate blood pressure [26] and have been shown to destabilize the effect of main classes of antihypertensive drugs [27]. 
Factors associated with prevalence, awareness, and control of hypertension

The odds ratios for the prevalence of hypertension as shown in Table 3, suggests that the frequency of hypertension gradually increased with increasing age up to the age of 84 years, then declined with further ages. Other studies in comparable settings have reported similar observations $[15,23,28]$. Individuals who reach a very old age above 85 years are generally healthier, and this may explain the declining prevalence of hypertension in the oldest age group.

Obese individuals were about twice more likely to have hypertension compared to those with healthy weight. Numerous studies have reported higher frequency of hypertension in overweight and obese subjects $[9,15,23$, 28]. However, even though obesity may be an independent predictor of hypertension, there is potential interaction with other lifestyle factors such as physical activity and dietary habits.

Expectedly, individuals with high education attainment had more than twice higher odds of being aware of their hypertension status than those with low education. Education is a well elucidated determinant of health disparity, and such disparities have been shown to be more pronounced in later life phases [29]. Our findings underscore the need to target individuals with low educational attainment for hypertension screening and treatment.

There was also a higher level of awareness in individuals with other comorbidities such as obesity, heart diseases, stroke, and diabetes. These findings are consistent with other studies $[15,23,28]$. We considered that individuals with these comorbidities are more likely to have higher frequency visits to their treating physicians and are preferentially screened for hypertension.

The poor control of hypertension as observed in our study reflects difficulties in blood pressure control in later life phases, and similar findings have been reported in other studies $[9,14,23,28]$. Hypertensive participants who were taking multiple drug classes were more likely to attain blood pressure control targets compared to individuals on a single antihypertensive drug class. Beyond three combinations, further clinical effect was not statistically significant. It could be interpreted that individuals who were taking more than three antihypertensive drug classes probably had advanced hypertension or resistant hypertension that was more difficult to be controlled by treatment. These findings are supported by a recent clinical trial, that reported better control of blood pressure in individuals treated with more than one antihypertensive drug class as initiation therapy compared to those treated with single drug class or stepped-care approach [30]. The European Society of Hypertension (ESH) 2018 guidelines recently recognized that, monotherapy treatment approach was generally ineffective for high risk hypertensive patient groups - those in grade 2 and 3 hypertension - and recommends multiple antihypertensive drug treatment, starting with two antihypertensive drug classes and up-titrating to three antihypertensive drug classes when hypertension control goals are not attained [31]. However, it should be emphasized that treatment goals for hypertension in the elderly poses significant challenges due to age-related physiological alterations, frailty and presence of multiple comorbidities [11, 32], and adverse health events associated with polypharmacy [33]. As such, individualized treatment strategy for the elderly is encouraged due to their special health conditions.

When blood pressure cut-off points for patients with diabetes were considered - as demonstrated in the subgroup analysis model - individuals with diabetes were shown to have significant difficulties with blood pressure control compared to non-diabetic individuals. Poor control of blood pressure among diabetic individuals is documented in other epidemiological studies [15, 23]. Several complex and inter-related biological changes may explain this potential resistance to antihypertensive drugs. Diabetes, which is believed to exacerbate stiffening of arteries, is also associated with higher risk of renal impairment and cardiovascular complications [34]. These complications have negative implications on blood pressure control. Moreover, volume overload which is commonly reported in persons with diabetes and associated with diabetic nephropathy, is believed to cause resistant hypertension [35]. However, other authors posit that difficulties in control of blood pressure in persons with diabetes maybe a result of inadequate clinical management, particularly, inadequate and inappropriate antihypertensive medication doses, drug class combinations, and poor compliance [36].

\section{Implications for practice and research}

There is need to improve screening of elderly population groups, especially those with a low level of education and those perceived to be at high risk of hypertension due to obesity or diabetes. Early treatment of hypertension may prevent irreversible arterial damage especially, in older persons who are at higher risk for vascular injury [5], and reduce risk of stroke and heart attack [25]. It should be noted, however, that treatment of hypertension especially in the very old, should be considered on the balance between risk and benefits for individual patients [11]. Evidence on the ideal blood pressure targets and safest hypertension regimen for this age group remains inconclusive [11, 25, 37]. Nonetheless, the importance of adequate clinical management of hypertension including multiple antihypertensive drug treatment especially in older adults with diabetes should be considered. 


\section{Strengths and limitations}

The study methods were highly standardized and consistent with widely recognized guidelines. As a population-based study, we recruited noninstitutionalized participants and employed comprehensive medication use review procedures. Our findings are therefore, plausible and comparable with similar studies. However, the blood pressure measurements were performed on a single visit; hence, white-coat hypertension and masked hypertension could be possible [38]. As a result, there might be a potential overestimation of prevalence of hypertension and underestimation of the controlled hypertension. Moreover, consistent with the general limitations of cross-sectional studies, the possibility of residual confounding as well as potential overestimation of some associations due to use of odds ratios instead of prevalence ratios [39] cannot be ruled out. Some of our variables were self-reported and could not be objectively verified at the time of the study.

\section{Conclusion}

Our study identified relevant health gaps on awareness, treatment and control of hypertension in older people aged 65-94 years in Germany. Screening for hypertension would particularly be useful among older adults with low educational attainment, who were observed to have low awareness of their hypertension status. Even though we observed that individuals taking three classes of antihypertensive drugs were more likely to have controlled hypertension compared to those taking a single class of antihypertensive drugs, a guarded, more individualized treatment approach should be considered when dealing with elderly subjects.

\section{Abbreviations}

BMI: Body mass index; CVD: Cardiovascular diseases; Cl: Confidence Interval; DBP: Diastolic blood pressure; EPV: Events per variable; IQR: Interquartile range; KORA: Cooperative health research in the Augsburg Region; OR: Odds ratio; SBP: Systolic blood pressure; SD: Standard deviation

\section{Acknowledgements}

We would like to extend our appreciation to all members Helmholtz Zentrum München, Uniklinikum Augsburg and affiliates, field staff and physicians who were involved in the planning and collection of data. We greatly appreciate all study participants.

\section{Authors' contributions}

SM performed statistical analyses, interpreted the data and drafted the manuscript. CM, MH, BT participated in conception and design of the study, methodological support, and commented on drafts of the manuscript. AP is the main coordinator of the KORA research project and assured quality and integrity in the conduct of the surveys. UA contributed in the conception and design of the study and offered methodological, statistical, data interpretation support and commented on drafts of the manuscripts. All authors read and approved the final version of the manuscript.

\section{Funding}

The KORA research platform was financed by the Helmholtz Zentrum München, German Research Center for Environmental Health, which is funded by the German Federal Ministry of Education and Research and by the State of Bavaria. The KORA Age project was financed by the German
Federal Ministry of Education and Research (BMBF FKZ 01ET0713) as part of the "Health in old age" program. The funders had no role in study design, data collection and analysis, decision to publish, or preparation of the manuscript.

\section{Availability of data and materials}

The full dataset supporting the conclusions of this article is available upon request and application from the Cooperative Health Research in the Region Augsburg (KORA; https://www.helmholtz-muenchen.de/kora/ueber-kora/ index.html).

\section{Ethics approval and consent to participate}

The KOR-Age 1 study was approved by the Ethics Committee of the Bavarian Medical Association and written informed consent was obtained from all participants before interview and physical measurements. The study was conducted according to the principles expressed in the Declaration of Helsinki.

Consent for publication

Not applicable.

\section{Competing interests}

The authors declare that they have no competing interests.

\section{Author details}

${ }^{1}$ Institute for Medical Informatics, Biometry, and Epidemiology, Ludwig-Maximilians-Universität München, Munich, Germany. ${ }^{2}$ Helmholtz

Zentrum München, German Research Center for Environmental Health $(\mathrm{GmbH})$, Independent Research Group Clinical Epidemiology, Ingolstädter Landstraße 1, 85764 Neuherberg, Germany. ${ }^{3}$ Chair of Epidemiology, Ludwig-Maximilians-Universität München, UNIKA-T, Augsburg, Germany. ${ }^{4}$ Helmholtz Zentrum München, German Research Center for Environmental Health $(\mathrm{GmbH})$, Institute of Epidemiology, Neuherberg, Germany. ${ }^{5}$ University Hospital of Augsburg, KORA Study Centre, Augsburg, Germany.

Received: 4 February 2020 Accepted: 24 June 2020

Published online: 02 July 2020

\section{References}

1. Roth GA, Johnson C, Abajobir A, Abd-Allah F, Abera SF, Abyu G, et al. Global, regional, and national burden of cardiovascular diseases for 10 causes, 1990 to 2015. J Am Coll Cardiol. 2017;70:1-25.

2. WHO. Cardiovascular diseases (CVDs). 2017. https://www.who.int/newsroom/fact-sheets/detail/cardiovascular-diseases-(cvds). Accessed 26 July 2019.

3. Mills KT, Bundy JD, Kelly TN, Reed JE, Kearney PM, Reynolds K, et al. Global disparities of hypertension prevalence and control: a systematic analysis of population-based studies from 90 countries. Circulation. 2016;134:441-50.

4. Forouzanfar MH, Liu P, Roth GA, Ng M, Biryukov S, Marczak L, et al. Global burden of hypertension and systolic blood pressure of at least 110 to 115 mm hg, 1990-2015. JAMA. 2017;317:165-82.

5. Neuhauser H, Sargans G. High blood pressure: a concern for everyone. In: Facts and Trends from Federal Health Reporting. Berlin: Robert Koch Institut; 2015.

6. Buford TW. Hypertension and aging. Ageing Res Rev. 2016;26:96-111.

7. Diederichs $C$, Neuhauser $H$. The incidence of hypertension and its risk factors in the German adult population: results from the German National Health Interview and examination survey 1998 and the German health interview and examination survey for adults 2008-2011. J Hypertens. 2017; 35:250-8.

8. Brindel P, Hanon O, Dartigues J, Ritchie K, Lacombe J, Ducimetiere P, et al. Prevalence,awareness, treatment and control of hypertension in the elderly: the Three City study. J Hypertens. 2006;24:51-8.

9. McDonald M, Hertz RP, Unger AN, Lustik MB. Prevalence, awareness, and management of hypertension, dyslipidemia, and diabetes among United States adults aged 65 and older. J Gerontol A Biol Sci Med Sci. 2009;64(2): 256-63.

10. Zdrojewski T, Wizner B, Wiecek A, Slusarczyk P, Chudek J, Mossakowska M, et al. Prevalence, awareness, and control of hypertension in elderly and very elderly in Poland: results of a cross-sectional representative survey. J Hypertens. 2016;34:532-8. 
11. Peters R, Beckett N, McCormack T, Fagard R, Fletcher A, Bulpitt C. Treating hypertension in the very elderly-benefits, risks, and future directions, a focus on the hypertension in the very elderly trial. Eur Heart J. 2014;35:1712-8.

12. Egan BM, Zhao $\mathrm{Y}, \mathrm{Axon} \mathrm{RN}$. US trends in prevalence, awareness, treatment and control of hypertension, 1988-2008. JAMA. 2010;303:2043-50.

13. Benetos A, Petrovic M, Strandberg T. Hypertension management in older and frail older patients. Circ Res. 2019;124:1045-60.

14. Seow LSE, Subramaniam M, Abdin E, Vaingankar JA, Chong SA. Hypertension and its associated risks among Singapore elderly residential population. J Clin Gerontol Geriatr. 2015;6:125-32.

15. Malhotra R, Chan A, Malhotra C, Ostbye T. Prevalence, awareness, treatment and control of hypertension in the elderly population of Singapore. Hypertens Res. 2010;33:1223-31.

16. Neuhauser $H$, Diederichs $C$, Boeing $H$, Felix $S B$, Junger $C$, Lorbeer $R$, et al. Hypertension in Germany. Dtsch Arztebl Int. 2016;113:809-15.

17. Grill E, Doring A, Heier M, Holle R, Ladwig KH, Linkohr B, et al. Multimorbidity and disability, findings from the KORA-Age study. BMC Proc 2013;7(Suppl 4):S10.

18. Peters A, Doring A, Ladwig KH, Meisinger C, Linkohr B, Autenrieth $\mathrm{C}$, et al. Multimorbidity and successful aging: the population-based KORA-age study. Z Gerontol Geriatr. 2011;44(Suppl 2):41-54

19. Kirchberger I, Meisinger C, Heier M, Zimmermann AK, Thorand B, Autenrieth $\mathrm{CS}$, et al. Patterns of multimorbidity in the aged population. Results from the KORA-Age study. PLoS One. 2012;7:e30556.

20. Empfehlungen zur Hochdruckbehandlung (Recommendations for the treatment of hypertension). 15th ed. Heidelberg: Deutsche Liga zur Bekämpfung des hohen Blutdruckes; 1999.

21. Lacruz ME, Kluttig A, Hartwig S, Loer M, Tiller D, Greiser KH, et al. Prevalence and incidence of hypertension in the general adult population: results of the CARLA cohort study. Medicine (Baltimore). 2015;94:e952.

22. Steigerwalt S. Management of hypertension in diabetic patients with chronic kidney disease. Diabetes Spectrum. 2008;21:30-6.

23. Ostchega Y, Dillon CF, Hughes JP, Carroll M, Yoon S. Trends in hypertension prevalence, awareness, treatment, and control in older U.S. adults: data from the National Health and nutrition examination survey 1988 to 2004. J Am Geriatr Soc. 2007;55:1056-65.

24. Bursac Z, Gauss CH, Williams DK, Hosmer DW. Purposeful selection of variables in logistic regression. Source Code Biol Med. 2008:3:17.

25. Goeres LM, Williams CD, Eckstrom E, Lee DS. Pharmacotherapy for hypertension in older adults: a systematic review. Drugs Aging. 2014;31: 897-910.

26. Johnson AG. NSAIDS and increased blood pressure. What is the clinical significance? Drug Saf. 1997;17:277-89.

27. White WB. Cardiovascular risk, hypertension, and NSAIDS. Curr Rheumatol Rep. 2007;9:36-43

28. Murphy CM, Kearney PM, Shelley EB, Fahey T, Dooley C, Kenny RA. Hypertension prevalence, awareness, treatment and control in the over 50s in Ireland: evidence from the Irish longitudinal study on ageing. J Public Health. 2016:38:450-8.

29. Oshio T. Widening disparities in health between educational levels and their determinants in later life: evidence from a nine-year cohort study. BMC Public Health. 2018;18:278.

30. MacDonald TM, Williams B, Webb DJ, Morant S, Caulfield M, Cruickshank JK, et al. Combination therapy is superior to sequential monotherapy for the initial treatment of hypertension: a double-blind randomized controlled trial. J Am Heart Assoc. 2017;(6):e006986.

31. Williams B, Mancia G, Spiering W, Agabiti Rosei E, Azizi M, Burnier M, et al. 2018 ESC/ESH guidelines for the management of arterial hypertension. Eur Heart J. 2018;39:3021-104.

32. Gobbens R, Jankowska-Polańska B, Chudiak A, Uchmanowicz I. Hypertension and frailty syndrome in old age: current perspectives. Card Fail Rev. 2017;3: 102-7.

33. Mukete BN, Ferdinand KC. Polypharmacy in older adults with hypertension: a comprehensive review. J Clin Hypertens (Greenwich). 2016;18:10-8.

34. Salvi P, Safar ME, Labat C, Borghi C, Lacolley P, Benetos A, et al. Heart disease and changes in pulse wave velocity and pulse pressure amplification in the elderly over 80 years: the PARTAGE study. J Hypertens. 2010;28:2127-33

35. Tsai YC, Tsai JC, Chiu YW, Kuo HT, Chen SC, Hwang SJ, et al. Is fluid overload more important than diabetes in renal progression in late chronic kidney disease? PLoS One. 2013;8:e82566
36. Eguchi K, Pickering T, Kario K. Why is blood pressure so hard to control in patients with type 2 diabetes. J Cardiometab Syndr. 2007;2:114-8.

37. Makin S, Stott DJ. Managing blood pressure in older adults. BMJ. 2018;362: k2912

38. Pinto E. Blood pressure and ageing. Postgrad Med J. 2007;83:109-14.

39. Tamhane A, Westfall A, Burkholder G, Cutter G. Prevalence odds ratio versus prevalence ratio: choice comes with consequences. Stat Med. 2016;35:5730-5.

\section{Publisher's Note}

Springer Nature remains neutral with regard to jurisdictional claims in published maps and institutional affiliations.
Ready to submit your research? Choose BMC and benefit from:

- fast, convenient online submission

- thorough peer review by experienced researchers in your field

- rapid publication on acceptance

- support for research data, including large and complex data types

- gold Open Access which fosters wider collaboration and increased citations

- maximum visibility for your research: over $100 \mathrm{M}$ website views per year

At BMC, research is always in progress.

Learn more biomedcentral.com/submissions 